\title{
THE EFFECT OF GROUTING REINFORCEMENT ON GROUNDWATER SEE- PAGE IN DEEP TUNNELS
}

\author{
Fusheng Liu, Guoyuan Xu, Wentong Huang, Shengbin Hu, Min Hu
}

School of Civil and Traffic Engineering, South China University of Technology (lfs_1981@126.com)

\begin{abstract}
To investigate the effect of grouting reinforcement rim on groundwater pressure and seepage discharge, a number of theoretical analyses have been conducted with the following assumptions: circular tunnel, radial stable and isotropic seepage. The solutions of the seepage flow and the hydraulic pressure distribution law are obtained by the calculations. According to the example, it proved that the grouting reinforcement can obviously decreased the hydraulic pressure acting on the lining and seepage discharge in drainage conditions. The seepage discharge of unlined tunnel calculated by the formulas is close to the actual value obtained from the monitoring data. It illustrates that this method is suitable for the similar tunnels. Additionally, on the basis of the correlation analysis, the water forces acting on the lining and the seepage flow decrease sharply at the beginning by reducing the permeability coefficient and increasing the thickness of the reinforcement rim. But when the reinforcement parameters reach to certain values, the water forces and seepage discharge keep stable regardless of whether the changes of the reinforcement parameters are taken.
\end{abstract}

Keywords: Radial Stable Seepage; Reinforcement parameter; Water Pressure; Seepage Discharge; Deep tunnels.

\section{INTRODUCTION}

With high speed development of our national economy, the highway was constructed on large-scale all around the country. Along the freeway in mountain area, many tunnels had to be constructed. The groundwater can cause a significant threat to the safety of the tunnels when excavating in water-rich areas [1-3]. The poor drainage management in the constructions has resulted in considerable depletion of the groundwater table, damaged soils and deterioration in the water resource in many regions [4]. As a ground improvement technique, grouting reinforcement is required to guarantee safe tunnel excavation and reduce the water discharge [5].

The important issues in the construction of the tunnels in water-rich regions are the designs of the lining and the grouting region parameters. According to groundwater control methodology, tunnels under groundwater table can be designed to either be sealed or drained. The lining of sealed tunnels is designed to withstand full hydrostatic pressures as well as the 
pressures generated by the ground, and the grouting rim cannot share the water pressure acting on the lining, whereas seepage forces are taken into account in the design of the lining of drained tunnels. In this case, estimations of the seepage force acting on the lining must be considered; the design of the grouting reinforcement coefficient is also important [6-8].

Usually two approaches, numerical methods and analytical methods, are used to estimate the seepage force acting on the lining in a drained tunnel. Yang et al. [9] presented an analytical solution for the anisotropic steady seepage of the circular tunnel based on the coordinate transformation method. Wang et al. [10] researched an analytical-numerical method for the hydraulic pressure of the deep buried tunnel. In-Mo Lee et al. [11] calculated studied the water pressure acting on the lining of the shallow buried tunnel based on the numerical method. A. Bobet [12] studied the effect of water pressure on tunnel lining during seismic loading. For deep tunnels, Atkinson and Mair [13] mentioned that, using an elastic approach, loads on the tunnel linings are the same, considering impermeable or fully-drained lining. For shallow tunnels, Schweiger et al. [14] and Lee and Nam [15] obtained less stresses in the linings with the consideration of the seepage force. Schweiger et al. [14] showed that the lining stresses in drained condition were about $75 \%$ of the value obtained when the full hydrostatic pressure is applied. By applying the drained condition at the tunnel invert only, Bilfinger [16] mentioned the possibility of significant reductions in lining loads due to the water level. InMo Lee et al. [5] evaluated the face stability in an underwater tunnel with steel pipereinforced multi-step grouting by taking seepage forces into account. LIN et al. [17] presented a forecast method of groundwater discharge in complex karst areas.

This study consists of two parts. First, the analytical solutions of the seepage flow and hydraulic pressure for the steady-state pore water pressure in a drained circular tunnel are performed. The second part focuses on the effect of grouting reinforcement on seepage force and groundwater discharge by an example.

\section{THE DISTRIBUTION LAW OF HYDRAULIC SEEPAGE PRESSURE}

In this method, it is assumed that: (1) the seepage flow is radial stable and isotropic; (2) the cross-section of the tunnel is circular.

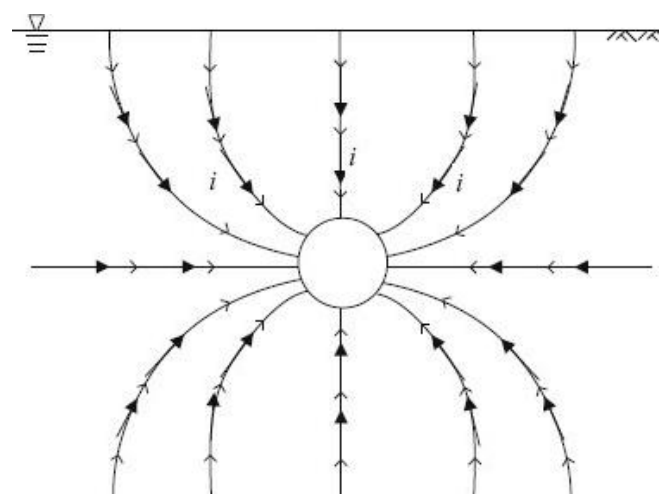

Figure 1. Flow net while tunneling under steady-state water flow 


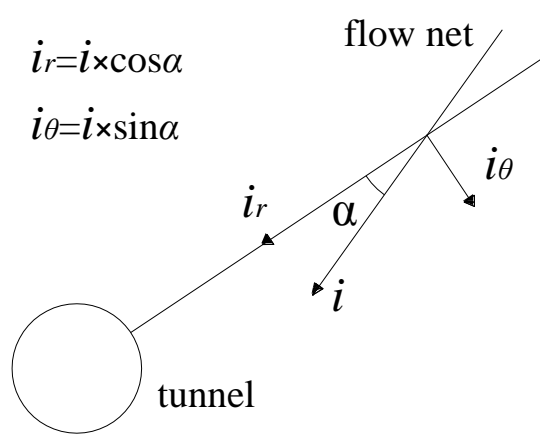

Figure 2. The radial and tangential component of hydraulic gradient

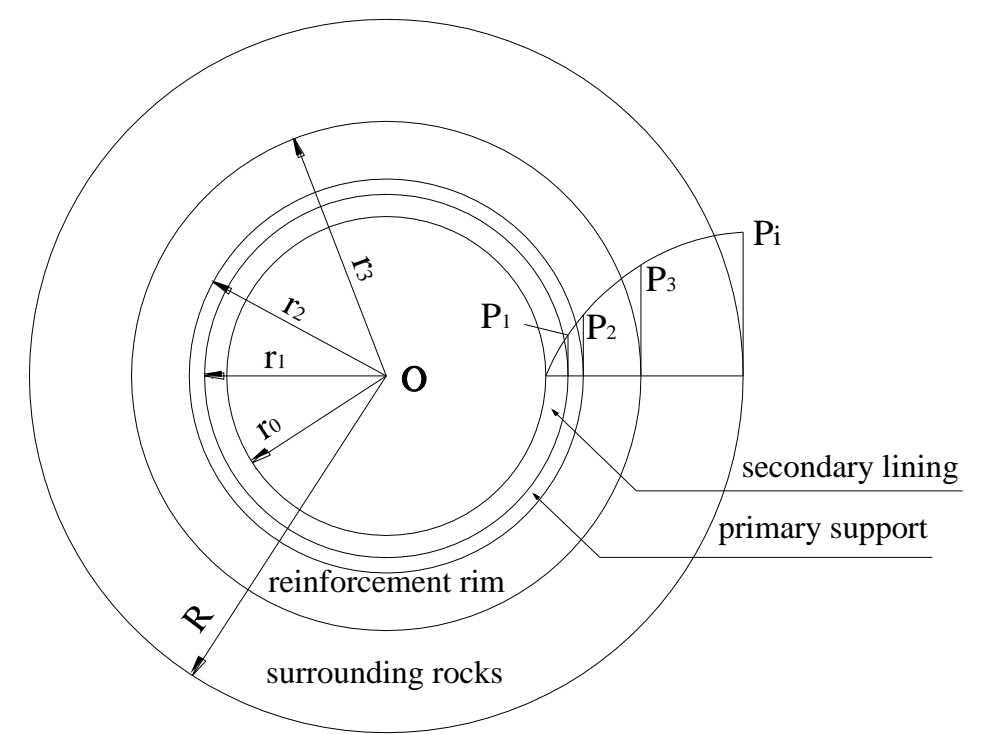

Figure 3. The whole distribution of hydraulic forces

While tunneling under steady-state water flow, the flow net of the groundwater flows as shown in Figure 1 develops. The hydraulic gradients touching all the flow lines could be divided into a radial component of hydraulic gradient $i_{\mathrm{r}}$ and a tangential component of hydraulic gradient $i_{\theta}$ with angle $\alpha$ as shown in Figure 2. The radial component of the groundwater flow affects most of the displacement of tunnel wall, and the seepage forces could be estimated in both of radial and non-radial flows by using radial component hydraulic gradient. So the radial component of hydraulic gradient was used to reflect the seepage effect. The whole distribution of hydraulic pressure as shown in Figure 3, and $r_{0}, r_{1}, r_{2}, r_{3}$ are the inner radius of lining, primary support, reinforced rim and surrounding rocks, respectively. $R$ is the radius of study area. The corresponding water forces are $P_{1}, P_{2}, P_{3}$ and the crude seepage field force $P_{\mathrm{i}}$.

For drained tunnels, it is assumed that the seepage potential only caused by the change of seepage pressure, so the hydraulic head $\varphi$ can be given as follows:

$$
\varphi=\frac{P_{w}}{\gamma}
$$

$P_{\mathrm{w}}$ is the seepage pressure, and $\gamma$ is the unit weight of water. 
Using Darcy's law and mass conservation, the two-dimensional steady-state water flow around the tunnel can be described by the following equation in the polar coordinate:

$$
\frac{\partial^{2} P_{w}}{\partial r^{2}}+\frac{1}{r} \frac{\partial P_{w}}{\partial r}=0
$$

In order to solve equation (2), two boundary conditions are needed: the water pressure at the inner wall of the lining is 0 , and the crude seepage field pressure $P_{\mathrm{i}}$ must be known.

According to the boundary condition and the seepage velocity continuity conditions, and calculating in each part, the hydraulic pressure in each part can be obtained as follows:

$$
\begin{cases}P_{w}=\frac{c \ln \frac{r}{r_{0}}}{(a+b) \ln \frac{r_{1}}{r_{0}} P_{i}} & \left(r_{0} \leq r \leq r_{1}\right) \\ P_{w}=\frac{c \ln \frac{r_{2}}{r}+b \ln \frac{r}{r_{1}}}{(a+b) \ln \frac{r_{2}}{r_{1}}} P_{i} & \left(r_{1} \leq r \leq r_{2}\right) \\ P_{w}=\frac{b \ln \frac{r_{3}}{r_{2}}+d \ln \frac{r}{r_{2}}}{(a+b) \ln \frac{r_{3}}{r_{2}} P_{i}} & \left(r_{2} \leq r \leq r_{3}\right) \\ P_{w}=\frac{a \ln \frac{r}{r_{3}}+b \ln \frac{R}{r_{3}}+d \ln \frac{R}{r}}{(a+b) \ln \frac{R}{r_{3}}} P_{i} & \left(r_{3} \leq r \leq R\right)\end{cases}
$$

Where, $a=k_{1} k_{2} k_{3} \ln \frac{R}{r_{3}}+k_{1} k_{2} k_{4} \ln \frac{r_{3}}{r_{2}} ; b=k_{1} k_{3} k_{4} \ln \frac{r_{2}}{r_{1}}+k_{2} k_{3} k_{4} \ln \frac{r_{1}}{r_{0}} ; c=k_{2} k_{3} k_{4} \ln \frac{r_{1}}{r_{0}}$; $d=k_{1} k_{2} k_{4} \ln \frac{r_{3}}{r_{2}}$.

$k_{1}, k_{2}, k_{3}, k_{4}$ are the permeability coefficients of the lining, primary support, reinforced region and surrounding rocks, respectively.

This formula is not only suitable for a circular tunnel, but also suitable for a tunnel with an arc shape.

If the tunnel is without grouting reinforcement rim, the distribution law of the hydraulic forces can be written as: 


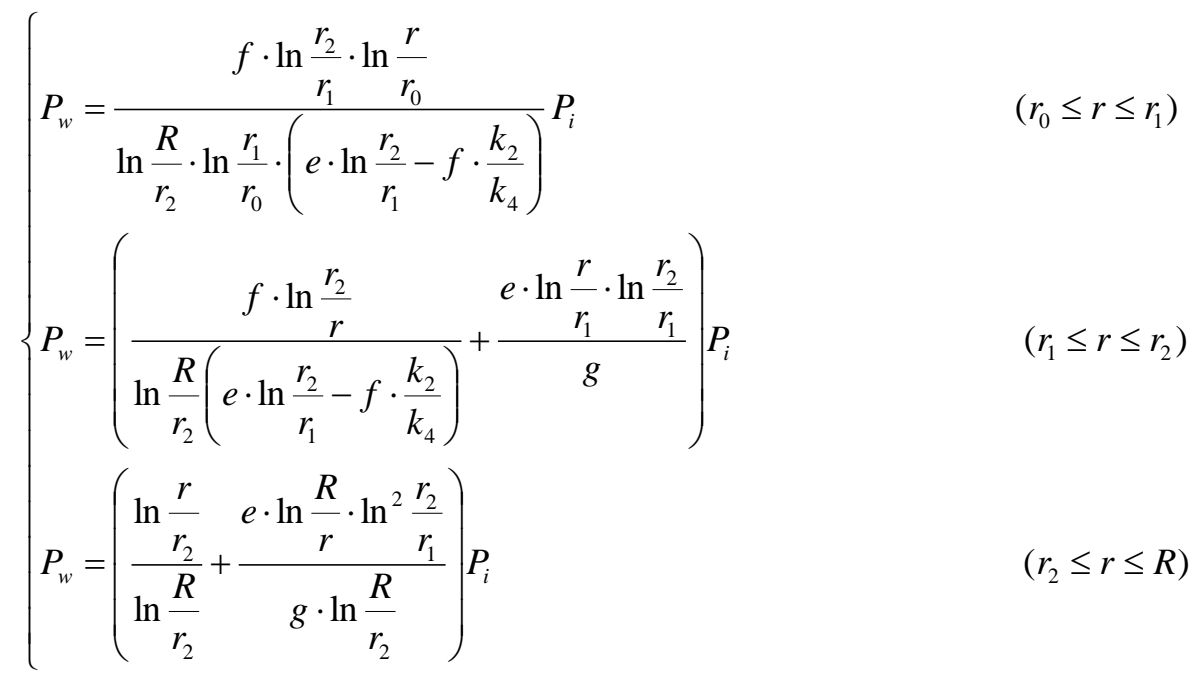

Where, $e=\left(k_{1} \cdot \ln \frac{r_{2}}{r_{1}}+k_{2} \cdot \ln \frac{r_{1}}{r_{0}}\right)\left(k_{2} \cdot \ln \frac{R}{r_{2}}+k_{4} \cdot \ln \frac{r_{2}}{r_{1}}\right) ; f=k_{2} \cdot k_{4} \cdot \ln \frac{r_{1}}{r_{0}} \cdot \ln \frac{r_{2}}{r_{1}} \cdot \ln \frac{R}{r_{2}}$;

$g=\left(\frac{k_{2}}{k_{4}} \cdot \ln \frac{R}{r_{2}}+\ln \frac{r_{2}}{r_{1}}\right)\left(e \cdot \ln \frac{r_{2}}{r_{1}}-f \cdot \frac{k_{2}}{k_{4}}\right)$.

Without any support and reinforcement measures, the hydraulic pressure of unlined tunnel can be expressed by one equation.

$$
P_{w}=\frac{\ln \frac{r}{r_{0}}}{\ln \frac{R}{r_{0}}} P_{i} \quad\left(r_{0} \leq r \leq R\right)
$$

\section{CALCULATION OF THE SEEPAGE DISCHARGE}

According to the Darcy Law, the seepage discharge $Q$ can be calculated by:

$$
Q=\frac{k A(r) d P_{w}}{\gamma d r}
$$

\subsection{When the tunnel is under construction}

Without any reinforcement measures, the seepage discharge of unsupported and unlined tunnel in unit length can be calculated by:

$$
\int_{0}^{P i} d P_{w}=\frac{Q_{m} \gamma}{2 \pi k_{4}} \int_{r_{2}}^{R} \frac{1}{r} d r
$$


According to the equation (5), then

$$
Q_{m}=\frac{2 \pi k_{4}}{\gamma \ln \frac{R}{r_{2}}} P_{i}
$$

Similarly, when the primary support and reinforcement rim had been built, the seepage discharge of tunnel without lining in unit length can be got as:

$$
Q_{0}=\frac{2 \pi k_{2} b}{\gamma \ln \frac{r_{2}}{r_{1}}(a+b)} P_{i}
$$

\subsection{When the tunnel is in service}

When the secondary lining, primary support and reinforcement rim had been built completely, the seepage discharge through the secondary lining can be calculated according to the equations (3) and (6).

$$
Q_{1}=\frac{2 \pi k_{1} c}{\gamma \ln \frac{r_{1}}{r_{0}}(a+b)} P_{i}
$$

If the tunnel is without reinforcement rim, the seepage flow through the secondary lining can be obtained as follows.

$$
Q_{1}^{1}=\frac{2 \pi k_{1} f \ln \frac{r_{2}}{r_{1}}}{\gamma \ln \frac{r_{1}}{r_{0}} \ln \frac{R}{r_{2}}\left(e \ln \frac{r_{2}}{r_{1}}-f \frac{k_{2}}{k_{4}}\right)} P_{i}
$$

In fact, water is not outflow through the lining because of the waterproof board behind the lining. It is discharged through the drainage system behind the waterproof board. In order to calculate simply, the effect of the drainage system is often generalized as the permeability of the lining.

How to determine the equitable permeability of the secondary lining is a key problem. The water plugging effect of secondary lining can be expressed by the coefficient $\beta$.

$$
\beta=\frac{Q_{0}-Q_{1}}{Q_{0}}
$$

Equations (9), (10) and (12) lead to the Equation (13) as follows: 


$$
\beta=1-\frac{c k_{1} \ln \frac{r_{2}}{r_{1}}}{b k_{2} \ln \frac{r_{1}}{r_{0}}}
$$

According to the detection data of water discharge before and after secondary lining have been built, the coefficient $\beta$ can be got by the equation (12). Then, the equitable permeability coefficient of the secondary lining can be obtained on the basis of the equation (13).

\section{APPLICATION IN THE FANGDOUSHAN TUNNEL}

The Fangdoushan extra-long tunnel is located in Shanghai-Chengdu highway, with a total length of approximately 7600 meters. The surrounding rocks in K58+630 K58+730 is weak mudstone, and the lining section of the tunnel as shown in Figure 4. The thickness of the grouting reinforcement rim is 6 meters, and the grouting material is cement-sodium silicate dual fluid. The study object is the upper semi-circle lining and the relevant primary support, reinforced region, surrounding rocks in K58+630 K58+730. According to the investigation data, the inner radius and permeability coefficients of each part as depicted in Table 1, and the crude seepage field pressure is $P_{i}=300 \mathrm{kPa}$ beyond the radius $R=60$ meters. The monitoring data of seepage discharge in different period as listed in Table 2.

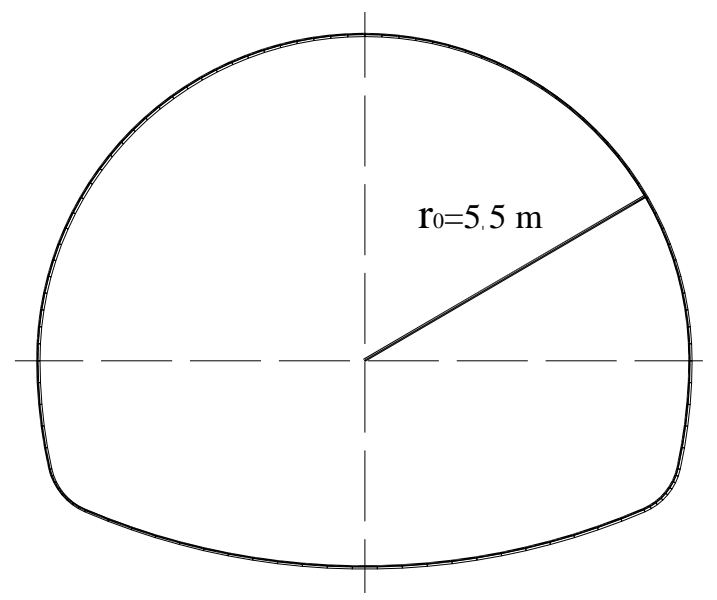

Figure 4. The lining section of the Fangdoushan tunnel

Table 1 . The dimensions and permeability coefficients list

\begin{tabular}{ccc}
\hline Objects & Inner radius $(\mathrm{m})$ & $\begin{array}{c}\text { Permeability coefficients } \\
(\mathrm{m} / \mathrm{d})\end{array}$ \\
\hline Secondary lining & $r_{0}=5.5$ & Remains to be calculated \\
Primary support & $r_{1}=5.95$ & $k_{2}=3.89 \times 10^{-4}$ \\
$k_{3}=1.81 \times 10^{-3}$ \\
Grouting reinforcement rim & $r_{2}=6.15$ & $k_{4}=0.54$ \\
Unreinforced surrounding & $r_{3}=12.15$ & \\
rocks & &
\end{tabular}


Table 2. The monitoring data of water discharge in different period

\begin{tabular}{cccc}
\hline Period & $\begin{array}{c}\text { Just after the exca- } \\
\text { vation finished }\end{array}$ & $\begin{array}{c}\text { Before the second- } \\
\text { ary lining have been } \\
\text { built }\end{array}$ & $\begin{array}{c}\text { After the secondary } \\
\text { lining have been } \\
\text { built }\end{array}$ \\
\hline $\begin{array}{c}\text { Seepage discharge } \\
\left(\mathrm{m}^{3} / \mathrm{d}\right)\end{array}$ & 4233.60 & 1151.40 & 406.50 \\
\hline
\end{tabular}

According to the Table 2, the coefficient $\beta$ can be got by the equation (12).

$$
\beta=0.647
$$

Then, the equitable permeability coefficient of the secondary lining can be obtained by the equation (13).

$$
k_{1}=5.05 \times 10^{-4} \mathrm{~m} / \mathrm{d}
$$

According to the equations (3) and (10), the hydraulic pressure acting on the secondary lining and the seepage discharge through the lining can be calculated as follows:

$$
\begin{gathered}
P_{1}=75.371 \mathrm{kPa} \\
Q_{1}=0.304 \mathrm{~m}^{3} / \mathrm{d}
\end{gathered}
$$

If the tunnel is without reinforcement rim, the hydraulic pressure acting on the lining and the seepage flow could be calculated as follows based on the equations (4) and (11).

$$
\begin{aligned}
& P_{1}^{1}=190.738 \mathrm{kPa} \\
& Q_{1}^{1}=0.77 \mathrm{~m}^{3} / \mathrm{d}
\end{aligned}
$$

By equation (8), the calculated seepage discharge of the unlined and unsupported tunnel in unit length is

$$
Q_{m}=44.685 \mathrm{~m}^{3} / d
$$

The actual seepage discharge of the unlined and unsupported tunnel in unit length can be got from the monitoring data in Table 2 .

$$
Q_{m}^{1}=42.336 \mathrm{~m}^{3} / d
$$

The calculated value is close to the actual value, and the relative error between them is:

$$
\delta=5.26 \%
$$

Therefore, this method is useful to similar projects.

The distribution laws of the hydraulic pressure in the primary support, reinforcement rim and surrounding rocks as shown in Figure 5. 


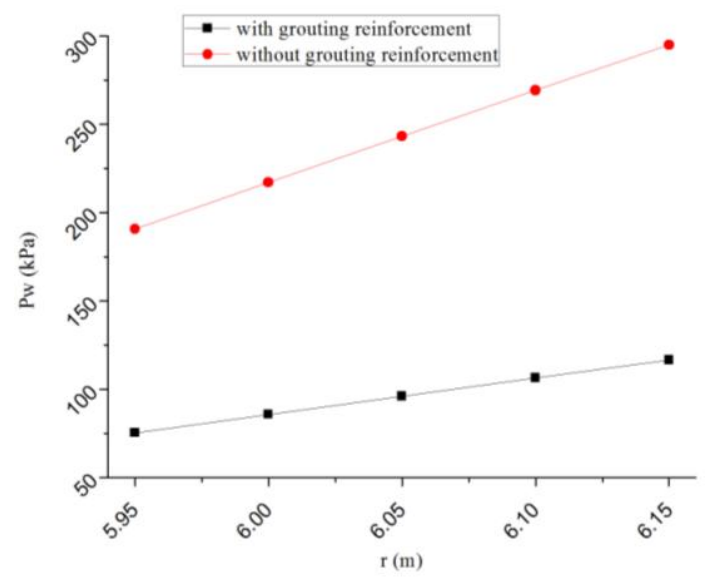

(a) The curve of hydraulic pressure in primary support

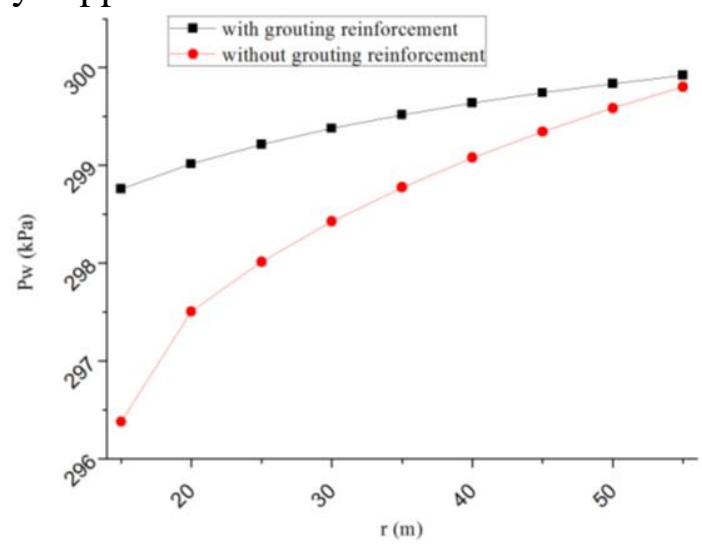

(c) The curve of hydraulic pressure in surrounding rocks

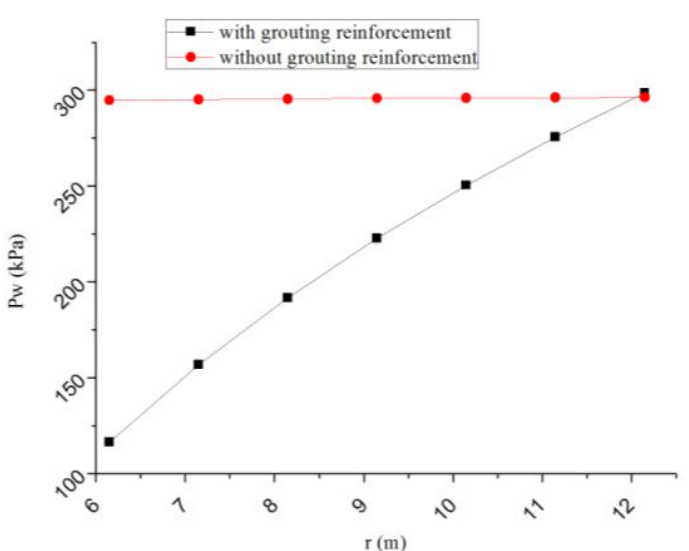

(b) The curve of hydraulic pressure in reinforcement rim

Figure 5. The curve of water pressure in the primary support, reinforcement rim and surrounding rocks

(Note: in figure (b), the red curve expresses the hydraulic pressure in surrounding rocks when the tunnel is without reinforcement)

By analyzing the results and Figure 5, the reduction factors of water pressure acting on the lining are about 0.25 (when the tunnel is with grouting reinforcement rim) and 0.64 (when the tunnel is without grouting reinforcement rim) compared to the crude seepage field pressure. Because of the grouting reinforcement rim, both the water pressure acting on the lining and the seepage discharge reduced by about $60.5 \%$.

The relation curves of $P_{1}-h$ and $Q_{1}-h$ are shown as the Figure 5. Where, $\lambda$ is the ratio of the permeability coefficient of the surrounding rocks to that of the reinforcement rim, $\lambda=k_{4} / k_{3}$; $h$ is the thickness of the grouting reinforcement rim; $P_{1}$ is the hydraulic pressure acting on the secondary lining, and $Q_{1}$ is the seepage discharge. 


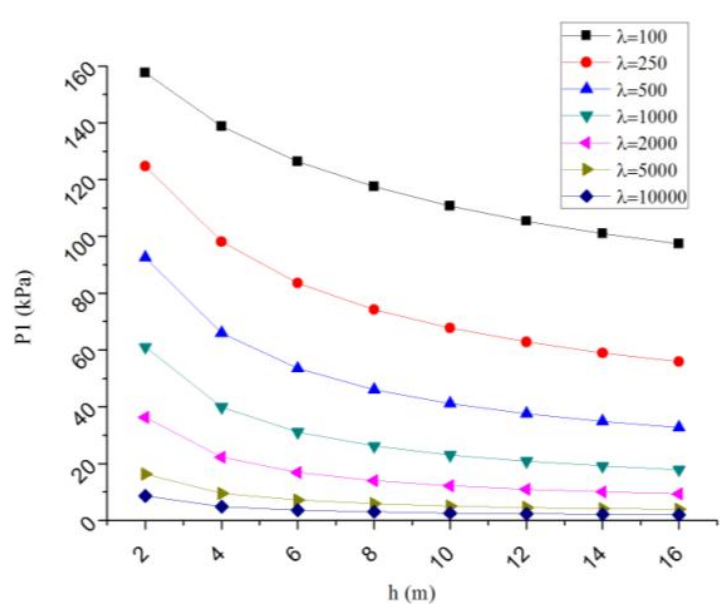

(a) The relation curve of $P_{1}-h$

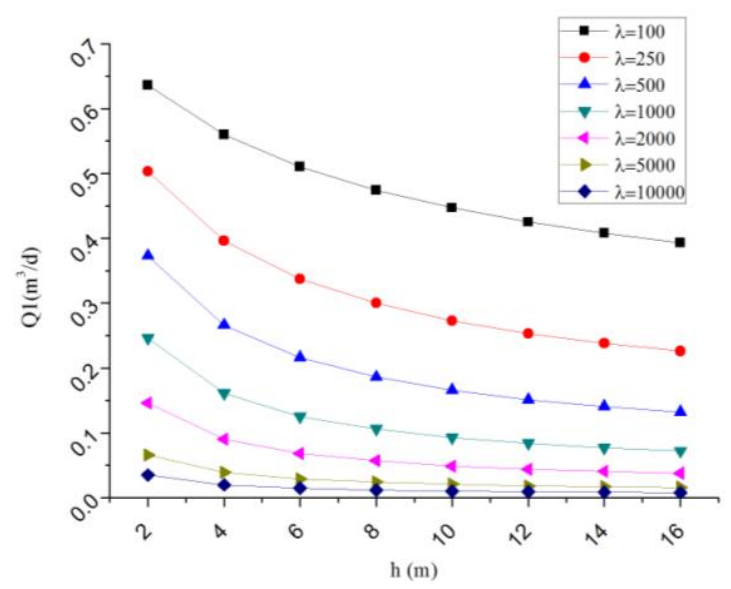

(b) The relation curve of $Q_{1}-h$

Figure 6. The relation curves of $P_{1}-h$ and $Q_{1}-h$

According to the Figure 6, with the increase of $\lambda$ and $h, P_{1}$ and $Q_{1}$ decreased sharply at the beginning. But the reduced speed get slow soon when $\lambda$ and $h$ reach certain values. It has no obvious effect to decrease the water pressure acting on the lining and the seepage discharge by reducing the permeability coefficient or increasing the thickness of the reinforced rim under this condition. Especially, when $\lambda>2000$ and $h>8$, the $P_{1}$ and $Q_{1}$ keep stable regardless of whether the changes of the reinforcement parameters are taken.

\section{DISCUSSION AND CONCLUSIONS}

By the previous analysis, an analytical method was proposed to study the effect of reinforcement rim on groundwater seepage, and brought the following results:

(1) The analytical solutions of the seepage discharge and the distributions of the hydraulic forces for the steady-state pore water pressure in a drained circular tunnel are obtained.

(2) According to the example, both the water pressure acting on the lining and the seepage discharge reduced by about $60.5 \%$ because of the grouting reinforcement rim. Comparing the calculated and actual seepage discharge of the unlined tunnel, it illustrates that this method is suitable for the similar projects.

(3) On the basis of the Figure 6, the water pressure acting on the lining and the water flow decreased sharply at the beginning by reducing the permeability coefficient and increasing the thickness of the reinforcement rim. Then, the reduced trend get slow soon when the permeability coefficient and the thickness of the reinforcement rim reach to certain values. Therefore, taking economic benefits into account, the changes of the reinforcement parameters cannot be taken blindly to decrease the hydraulic pressure and the water discharge. The optimal analysis of the actual conditions should be carried out to determine the reinforcement parameters in practical engineering.

\section{ACKNOWLEDGEMENTS}

This work is funded by the Natural Science Foundation of China (No.51078151). 


\section{REFERENCES}

[1] LI Xi-bing, ZHANG Wei, LI Di-yuan, WANG Qi-sheng. Influence of underground water seepage flow on surrounding rock deformation of multi-arch tunnel. J. Cent. South Univ. Technol, 15: 69-74, 2008.

[2] TSENG D J, TSAI B R, CHANG L C. A case study on ground treatment for a rock tunnel with high groundwater ingression in Taiwan. Tunnelling and Underground Space Technology, 16(3): 175-183, 2001.

[3] Young-Jin Shin, Ki-ll Song, In-Mo Lee, Gye-Chun Cho. Interaction between tunnel supports and ground convergence-consideration of seepage forces. International Journal of Rock Mechanics and Mining Sciences, 48(3): 394-405, 2011.

[4] WANG Li-ying, ZHAO Wei-guo. Forecasting groundwater level based on WNM with GA. Journal of Computational Information Systems, 7(1): 160-167, 2011.

[5] In-Mo Lee, Jae-Sung Lee, Seok-Woo Nam. Effect of seepage force on tunnel face stability reinforced with multi-step pipe grouting. Tunnelling and Underground Space Technology, 19: 551-565, 2004.

[6] Kyung-Ho Park, Joo-Gong Lee, Adisorn Owatsiriwong. Seepage force in a drained circular tunnel: An analytical approach. Can. Geotech. J., 45: 432-436, 2008.

[7] Ponlawich Arjnoi, Jae-Hyeung Jeong, Chang-Yong Kim, Kyung-Ho Park. Effect of drainage conditions on porewater pressure distributions and lining stresses in drained tunnels. Tunnelling and Underground Space Technology, 24: 376-389, 2009.

[8] HE Hong-zhong, WANG Xing-hua. Study on parameters of grouting reinforced rim during undersea tunnel. Technology of Highway and Transport, 5: 99-102, 2008.

[9] YANG Zhi-xi, YANG Lin-de. Analytic solution for anisotropic steady seepage into a circle-crossed tunnel. Journal of TongJi University, 29(3): 273-277, 2001.

[10] WANG Jian-xiu, YANG Li-zhong, HE Jing. The simulation of deep tunnel external water pressure by analytical-numerical method. Hydrogeology and Engineering geology, 3: 17-19, 2002.

[11] In-Mo Lee, Seok-Woo Nam. The study of seepage forces acting on the tunnel lining and tunnel face in shallow tunnels. Tunnelling and Underground Space Technology, 16: 3140, 2001.

[12] A. Bobet, Effect of pore water pressure on tunnel support during static and seismic loading. Tunnelling and Underground Space Technology, 18: 377-393, 2003.

[13] Atkinson, J.H., Mair, R.J.. Loads on leaking and watertight tunnel linings, sewers and buried pipes due to groundwater. Geotechnique, 33(3): 341-344, 1983.

[14] Schweiger, H.F., Pottler, P.K., Steiner, H.. Effect of seepage forces on the shotcrete lining of a large undersea cavern. In Proceeding, Int. Conf. Computer Methods and Advances in Geomechanics, 1503-1508, 1991.

[15] Lee, I.M., Nam, S.W.. The study of seepage forces acting on the tunnel lining and tunnel face in shallow tunnels. Tunnelling and Underground Space Technology, 16(1):3140, 2001.

[16] Bilfinger, W.. Impermeabilization versus drainage: some considerations regarding lining loads. Felsbau, 23(3):55-61, 2005.

[17] LIN Chuan-nian, LI Li-ping, HAN Xing-rui. Research on forecast method of tunnel water inrush in complex karst areas. Chinese Journal of Rock Mechanics and Engineering, 27(7): 1469-1476, 2008. 